\title{
CAPACITAÇÃO CONTINUADA PARA PROFESSORES QUE ATUAM COM ESTUDANTES EGRESSOS DE ESCOLAS DO CAMPO PARA AS ESCOLAS URBANAS DO MUNICÍPIO DE DOIS IRMÃOS DO BURITI/MS
}

\section{ARTIGO DE REVISÃO}

NASCIMENTO, Márcio Moreira Do ${ }^{1}$

NASCIMENTO, Márcio Moreira Do. Capacitação continuada para professores que atuam com estudantes egressos de escolas do campo para as escolas urbanas do Município de Dois Irmãos Do Buriti/MS. Revista Científica Multidisciplinar Núcleo do Conhecimento. Ano 05, Ed. 01, Vol. 07, pp. 79-88. Janeiro de 2020. ISSN: 24480959, Link de acesso: https://www.nucleodoconhecimento.com.br/educacao/estudantes-egressos

\section{RESUMO}

A presente pesquisa tem como principal objetivo compreender a importância da capacitação continuada para professores das escolas urbanas que não possuem experiência com a realidade da Educação no Campo e que atuam com estudantes do campo. No desdobramento apresentam-se as características efetivas da educação no campo, a legislação pertinente e a formação do professor do campo. A pesquisa é qualitativa, de levantamento bibliográfico com entrevista. Percebeu-se que os educadores estão despreparados para lidar com as diferenças culturais principalmente com a temática aqui envolvida. O estudo demonstra que, tanto o aluno egresso da escola rural quanto o professor da escola urbana se perdem em suas necessidades. Assim, a temática é bastante pertinente tendo em vista as diferentes possibilidades de formação.

\footnotetext{
${ }^{1}$ Mestrando em Geografia (UFMS-Aquidauana), Especialização em Gestão Escolar, Graduação em Pedagogia.
} 
Palavras-chave: Educação, Campo, formação de professores.

\section{INTRODUÇÃO}

A educação do campo, realidade pautada em leis a partir de o Brasil Imperial, entendese como uma educação orientada para pessoas que residem e dependem do meio rural. Há identificação de uma educação diferenciada, que respeita a forma de viver e realizar, retratando a cultura por meio da realidade da qual o educando está inerido. A partir daí os professores que atuam no campo acolhem a realidade do lecionando.

Segundo Souza (2008), nos anos de 1980, os assentamentos organizados do Movimento Sem Terra (MST), tornam visíveis as questões educacionais dos camponeses e trabalhadores rurais. Novos documentos foram apontando as necessidades de uma política pública própria para a de educação do campo.

Pela importância de diferenciar essa realidade, este trabalho propõe a construção de uma asserção de capacitação continuada de professores, que atuam com educandos do campo inseridos nas escolas urbanas. Que se dediquem a interpretar o contexto educativo construído durante do contato de educandos egressos da Educação no Campo para as escolas urbanas, com o intuito de reduzir as barreiras e estimular os educandos a seguir as etapas do ensino fundamental e médio, várias vezes complicados nos primeiros anos de inclusão social nas escolas urbanas.

A partir de estudo qualitativa, a partir de observações e relatos de experiências dos professores que atuam com educandos egressos das escolas rurais e matriculados nas escolas municipais de Dois Irmãos do Buriti/MS, estuda-se o universo dos significados, as causas, os princípios na percepção do professor, permitindo investigar a realidade social do educando em seus distintos meios de convivência.

Sem aprofundar no processamento histórico da Educação no Campo, realiza-se uma reconsideração bibliográfica a começar por Leis, Decretos, Textos Oficiais e funções publicados em bancos de dados confiáveis, como Scielo, Portal MEC entre outros, estruturando esse estudo, após a justificativa do tema, em três partes. Na primeira 
contextualizam-se alguns conceitos e princípios da educação do campo. Na segunda a leis brasileira a respeito de da Educação no Campo e na terceira a formação do formador.

\section{JUSTIFICATIVA}

A educação no campo, diferenciada daquela oferecida nas escolas urbanas, ganha identificação do Sugestão Nacional de Educação, por meio da Mudança CNE/CEB 1, de 03 de abril de 2002 (BRASIL, 2002).

O reconhecimento de que as pessoas que vivem no campo têm direito a uma

Educação diferenciada daquela oferecida a quem vive nas cidades é recente e inovador, ganhou força a partir da instituição, pelo Conselho Nacional de Educação, das Diretrizes Operacionais para a Educação Básica nas Escolas do Campo. Esse reconhecimento extrapola a noção de espaço geográfico e compreende as necessidades culturais, os direitos sociais e a formação integral desses indivíduos (BRASIL, 2007p.9).

Nesse entrecho, a formação do professor estimula uma percepção de educação pautada na discussão técnica e, contém a importância de proporcionar educação adequada a indivíduos identificada como camponeses. Não obstante, não prepara o formador para praticar com educandos do campo inseridos nas escolas urbanas, especialmente, aqueles que de modo algum tiveram contato com o ensino nas escolas rurais e acabam se deparando com essa realidade.

De acordo com Fernandes (2011, p.1):

[...]. Embora o acesso ao ensino fundamental seja dado como universalizado em todo o Brasil, a persistência das desigualdades educacionais entre as zonas rural e urbana faz lembrar os tempos lentos da história. Em pleno século 21, milhares de crianças e jovens enfrentam inúmeras barreiras para continuar os estudos e concluir as etapas do fundamental e do médio, em cenário que muitas vezes evoca os 
primeiros anos do século passado. Os números das matrículas no campo mostram que as políticas educacionais na área rural priorizam o atendimento escolar apenas até o $5^{\circ}$ ano do ensino fundamental. Daí em diante, o estudante deve, em geral, buscar outras cidades caso queira continuar a estudar [...].(FERNANDES, 2011, p.1)

Nessa prospectiva, se faz preciso traduzir o entrecho educativo construído durante do narrado de educandos egressos da Educação no Campo para as escolas urbanas, retratando as dificuldades enfrentadas e sugerir técnicas para reduzir as barreiras e estimular os educandos a seguir as etapas do ensino fundamental necessário e médios várias vezes complicados nos primeiros anos de introdução comunitário nas escolas urbanas.

Por experiência desse pesquisador, com graduação em pedagogia, ao observar que educandos egressos das escolas rurais, inseridos nas escolas urbanas, no município de Dois Irmãos do Buriti/MS, percebe-se que eles se deparam com a exclusão social no meio educacional, principalmente a maior parte que estuda até o $5^{\circ}$ ano do Ensino Fundamental nas escolas rurais. Entende-se que isto acontece por causa de à falta de entendimento ou experiência dos professores com a educação do campo.

Considerando que o município possui cinco (cinco) escolas no campo, como escolas extensões urbanas, usando o mesmo currículo educativo das escolas urbanas, mantendo em média 450 educandos matriculados constantemente e 28 professores, torna-se fundamental estimular a capacitação continuada para professores, tanto das escolas no campo, quanto das escolas urbanas, para reconhecer a dinâmica da educação das escolas rurais e estruturar papel de mediador no processamento de inclusão do aluno do campo nas escolas urbanas. 


\section{EDUCAÇÃO NO CAMPO}

\subsection{CONCEITOS E PRINCÍPIOS}

De acordo com Souza (2008), a Educação no Campo possui atingido lugar na agenda política nas instâncias municipal, estadual e federal nos últimos anos, como fruto dos confrontos dos movimentos e organizações sociais dos trabalhadores rurais. A fecundação de Educação no Campo valoriza as competências dos camponeses e possui o campo como lugar de trabalho, estabelecimento e como lugar da construção de novas possibilidades de reprodução social e de desenvolvimento sustentável.

A princípio, a Lei de Diretrizes e Bases da Educação (LDB) Lei no 4.024, de 1961, promovia a educação nas áreas rurais com o intuito de evitar a migração dos indivíduos do campo para as cidades e dessa maneira fazer complicações habitacionais aumentar os cinturões de mendicidade, bastante comum nos grandes centros urbanos (BRASIL, 2011, p. 16).

No âmbito das políticas públicas para a educação, pensava-se - e muitos pensam ainda - que o problema a ser resolvido para a educação das populações que vivem fora das cidades decorria apenas da localização geográfica das escolas e da baixa densidade populacional nas regiões rurais. Isso implicava, entre outras coisas, a necessidade de serem percorridas grandes distâncias entre casa e escola e o atendimento de um número reduzido de estudantes, com consequências diretas nos gastos para a manutenção do então denominado ensino rural (BRASIL, 2007, p. 10).

A Lei de Diretrizes e Bases da Educação no 9.394 (BRASIL, 1996), em dezessete anos da sua criação, representa aumento na luta das populações rurais, ao dizer-se em seu texto-base às peculiaridades do campo, garantindo o direito a uma educação diferenciada e abrindo capacidade para a construção a e consolidação de escolas organizadas com outra concepção tanto em sua estrutura de gestão colegial quanto epistemológica e didático metodológica. 
Art. 28. Na oferta de educação básica para a população rural, os sistemas de ensino promoverão as adaptações necessárias à sua adequação às peculiaridades da vida rural e de cada região, especialmente: I - conteúdos curriculares e metodologias apropriadas às reais necessidades e interesses dos estudantes da zona rural; II organização escolar própria, incluindo adequação do calendário escolar às fases do ciclo agrícola e às condições climáticas; III - adequação à natureza do trabalho na zona rural (BRASIL,1996)

A Resolução no 2/2008 (BRASIL, 2008, p. 1), estabelece:

Art. 1ํA Educação no Campo compreende a Educação Básica em suas etapas de Educação Infantil, Ensino Fundamental, Ensino Médio e Educação Profissional Técnica de nível médio integrada com o Ensino Médio e destina-se ao atendimento às populações rurais em suas mais variadas formas de produção da vida - agricultores familiares, extrativistas, pescadores artesanais, ribeirinhos, assentados e acampados da Reforma Agrária, quilombolas, caiçaras, indígenas e outros.

Perante essas considerações, entende-se que a educação no campo propõe práticas pedagógicas que respeita a essência e os interesses culturais dos trabalhadores do campo. A intenção é preservar o território e fortalecer ações ligadas à educação orientada para a realidade reinante do local.

\subsection{LEGISLAÇÕES BRASILEIRAS}

Segundo a Secretaria de Educação Continuada, Alfabetização e Diversidade colegiados que trabalham junto ao governo federal para ampliar institucionalização, a disseminação e o enraizamento das políticas públicas para a Educação do Campo, foram criados, entre eles: o Conselho Nacional de Desenvolvimento Rural Sustentável para Agricultura Familiar, em 1999 e o Grupo Permanente de Trabalho de Educação no Campo, criado em 2003 (BRASIL, 2007, p. 15). 
A causa de informação, Souza (2008), afirma que: As discussões sobre Educação no Campo foram fortalecidas a partir das experiências do MST, em especial na organização dos espaços públicos, como o I Encontro Nacional de Educadores da Reforma Agrária (1997) e a I Conferência Nacional Por uma Educação Básica do Campo (1998). Na década de 1990, vários estados organizaram projetos de Educação de Jovens e Adultos, acumulando experiências para a elaboração do Programa Nacional da Educação na Reforma Agrária (1998). (SOUZA,2008, p.7)

A SECAD, fabricada em 2004, que possui uma coordenação específica para a educação rural, é encarregado, no meio nacional, tanto pelo ensino na zona rural, quanto pela alfabetização e educação de jovens e adultos, educação ambiental, educação em direitos humanos, educação colegial indígena e variedade étnico-racial. (FERNANDES, 2007, p. 02).

A LDB de 1996 reconhece, em seus Art. 3ํㅜ 23, 27 e 61, a diversidade sociocultural e o direito à igualdade e à diferença, possibilitando a definição de diretrizes operacionais para a educação rural sem, no entanto, romper com um projeto global de educação para o país. A ideia de mera adaptação é substituída pela de adequação, o que significa levar em conta, nas finalidades, nos conteúdos e na metodologia, os processos próprios de aprendizado do estudante e o que é específico do campo. Permite, ainda, a organização escolar própria, a adequação do calendário escolar às fases do ciclo agrícola e às condições climáticas (BRASIL, 2007, p.16).

O Plano Nacional de Educação (PNE), aprovado pela Lei № 10.172/2001 estabelece tratamento diferenciado para as escolas rurais. As Diretivas Operacionais para a Educação Básica das Escolas do Campo, similarmente aprovada em 2001, pelo Conselho Nacional de Educação, preocupa-se com o reconhecimento e a valorização da diversidade dos povos do campo, como a formação diferenciada de professores e 
a adequação dos conteúdos às peculiaridades locais entre outros entre mais (BRASIL, 2007, p.17).

De acordo com o parágrafo Único do art. 2‥ da Mudança CNE/CEB 1, de 03 de abril de 2002 (BRASIL, 2002):

Parágrafo único. A identidade da escola do campo é definida pela sua vinculação às questões inerentes à sua realidade, ancorando-se na temporalidade e saberes próprios dos estudantes, na memória coletiva que sinaliza futuros, na rede de ciência e tecnologia disponível na sociedade e nos movimentos sociais em defesa de projetos que associem as soluções exigidas por essas questões à qualidade social da vida coletiva no país. (BRASIL, 2002).

De acordo com Souza (2008), a LDB 9394/96, marca a colocação da Educação no Campo na agenda política educacional ao afirmar seu artigo 28, a eventualidade de conformidade curricular e metodologias apropriadas ao meio rural; flexibilizar a disposição colegial, com conformidade do calendário escolar.

O Sistema Estadual de Ensino de Mato Grosso do Sul, está disposto na Lei oㅜ 2.787 de 24 de dezembro de 2003 (BRASIL, 2003), em seu Art. 41, Sinal único regulamenta que: " O Quantidade Público oferecerá ensino exclusivo para escolas rurais e para as comunidades indígenas". E de acordo com o Art. 50 dessa Lei, na oferta da educação básica pelas escolas rurais e pelas escolas indígenas, serão necessárias adaptações às suas peculiaridades, mediante lei do Conselho Estadual de Educação. Precisa observar os conteúdos curriculares, as metodologias, os programas e as aquilo que se faz voltadas para a superação e transformação das condições de vida do campo e das comunidades indígenas, propiciando a estas a autonomia, considerando a organização escolar própria, adequação de calendário escolar; adequação à natureza do trabalho no campo e das comunidades indígenas.

De acordo com o sinal único do art. 50 da Princípio № 2.787 (BRASIL, 2003): 
O ensino será ministrado em Língua Portuguesa, assegurado às comunidades indígenas a utilização de suas línguas maternas, bem como processos próprios de aprendizagem, conforme normas específicas do órgão normativo do Sistema Estadual de Ensino. (BRASIL,2003).

Fundamental realçar que essa Lei deve ser usada para garantir direitos e deveres dentro da disposição do sistema de ensino com base nas suas atribuições e competências, procurando efetivar o verdadeiro processo de construção da lei junto ao sistema de educação.

\subsection{FORMAÇÃO PROFESSORES DA EDUCAÇÃO DO CAMPO}

Qualquer indivíduo conhece a diferença entre a vida na cidade e a vida no campo. No entanto, na execução, nem sempre a distinção é precisa, pois, muitos elementos, dado o processo de globalização, se assemelham. Dessa maneira geralmente a diferenciação mais popular está na definição da paisagem. Cidade vista como concentração de casas e edifícios, transito exagerado, poluição e campo como um ambiente rural, agrícola ou pecuário, que envolve o cultivo da terra e criação de animais. Dessa maneira, no momento em que os educandos são rurais e a escola é urbana as diferenças culturais são claramente evidenciadas.

De acordo com Fernandes (2011), a formação, dos professores que atuam no campo é desafiadora, não apenas pela falta de profissionais com nível superior, porém similarmente pela variedade das realidades sociais encontradas e por prevalecerem o formador polivalente e as classes multisseriadas, que exige muito esforço e qualificação dos professores para trabalhar com educandos de distintas séries e idades ao mesmo tempo, na mesma dependência.

O estudo do Observatório da Educação mostra que em 2007 havia 311 mil professores no ensino fundamental e médio regulares no campo. Esse número representa $17 \%$ dos docentes em exercício no país. Deles, 
$61 \%$ não têm formação superior, o que significa um contingente de aproximadamente 178 mil professores (FERNANDES, 2001, p.5).

Sem dúvida, professores da área rural enfrentam sobrecarga de trabalho e alguns, recebem salários inferiores aos da zona urbana, pela falta de apreciação superior, que pode ser ideia com influência para meia-tinta de educação no campo.

De acordo com a SECAD/DF (BRASIL, 2007).

A proporção de professores leigos, embora tenha declinado, de 2002 a 2005, de 8,3\% para 3,4\%, ainda é elevada, já que 6.913 funções docentes são exercidas por professores com até o ensino fundamental e apenas $21,6 \%$ dos docentes das séries iniciais do ensino fundamental cursaram nível superior. Nas séries finais do ensino fundamental, o percentual de docentes com apenas o ensino médio corresponde a $46,7 \%$ e, com formação superior, $53,1 \%$. Já no ensino médio, $11,3 \%$ do professorado está atuando no mesmo nível de sua formação [...] (BRASIL, 2007, p. 22).

Entende-se que a formação específica e adequada, especialmente de nível superior para a educação no campo é uma maneira de valorizar o professor com conteúdo mais apurado e criar o entendimento científico no processamento de formação específica para a realidade da academia rural.

\section{RESULTADOS E DISCUSSÕES}

O presente estudo baseou-se em pesquisa documental e realização de entrevistas, com 15 professores da rede municipal de ensino, com idade entre 22 e 48 anos, trabalhando como professores entre 3 a 15 anos de experiência, dos quais, todos lidam com crianças egressas das escolas rurais, inseridas nas escolas urbanas, há ao menos 3 anos, com quase $20 \%$ da galera formada por estes educandos.

Valendo ressaltar, que nas escolas rurais do município de Dois Irmãos do Buriti/MS, o projeto educativo empregado é o mesmo da academia urbana. Dessa forma, o 
propósito da entrevista foi diagnosticar a preocupação de alguns educadores do município e significar a presença do aluno rural na escola urbana sob o ponto de vista desses profissionais.

Em correlação ao entendimento dos conteúdos curriculares que envolvem a educação no campo, cursos de capacitação ou graduação especifica, somente um dos entrevistados cursou Especialização em educação no Campo, os demais não têm nenhuma compreensão do que seja a educação no campo.

Dentre as dificuldades mais frequentes enfrentadas pelos professores em sala de aula com estes educandos, prevalece a canseira dos educandos devido a necessidade de levantar cedo para embarcar no transporte escolar, e a quantidade de faltas as aulas por dificuldade com o transporte, especialmente em dias chuvosos, que deixam as estradas rurais intransitáveis.

Perante essa situação, o formador se vê obrigado a repetir o conteúdo para não os prejudicar. Similarmente, como alternativa, trabalhos em grupos e dinâmicas nas aulas para que esses estudantes acompanhem o conteúdo.

As questões trabalhadas foram: Você acredita que a realidade campesina educativa, embora dos avanços também apresenta algumas desvantagens em correlação a educação urbana? Quais as desvantagens de maior valia? Todos responderam que efetivamente, também há desvantagens. Apontaram como desvantagens a falta de investimento tecnológico nas escolas rurais, a dificuldade de acesso a essas tecnologias, ensino dos professores e a canseira dos educandos que precisam levantar cedo demais para embarcar no transporte escolar.

Percebe-se diretamente que o atraso da educação no campo e da realidade rural por parte dos professores, refletem bem nas respostas acima, pois, há valores ignorados. Entretanto, observa-se que não é desinteresse do professor, apenas seu ponto de vista está pautado sob a orientação pedagógica urbana, onde a equipe de educadores preocupa-se em cumprir as determinações da Secretaria de Educação, voltadas muito mais para a questão currículo do que diversidade cultural. 
Por outro lado, todos os professores se mostram sensíveis as dificuldades enfrentadas por educandos rurais e acabam recorrendo a explicações assistencialistas, do tipo desenvolver trabalhos em grupo para que o aluno possa participar, mesmo não assistindo a aula. Naturalmente, os estudantes são privilegiados em termos de avaliação. Os posicionamentos a favor da especificidade da Educação no Campo como capacitação continuada para professores do setor rural, firmam-se no entrecho desse estudo ao supervisionar que o continuo urbano

Nesse contexto, a capacitação continuada para educandos que atuam com estudantes egressos das escolas rurais nas escolas urbanas, se dá pela importância de um tratamento especifico do professor com propostas pedagógicas que valorizem o ensino construído na escola rural e estimule transformação para melhoria e convivência coletiva de forma solidaria entre educandos rurais e urbanos.

Esse estudo evidenciou que não há inadequação da escola urbana de Dois Irmãos do Buriti/MS à realidade rural, mas insuficiência de professores capacitados para a educação do campo. Pelo resultado, nota-se a importância de viabilizar capacitação continuada para os professores. Desta forma, essa pesquisa será apresentada à Secretaria Municipal de Educação do município de Dois Irmãos do Buriti/MS com o propósito de estimular a capacitação continuada dos professores para educação no campo.

\section{CONCLUSÃO}

O trabalho apresenta a importância da Formação Continuada para professores das escolas urbanas que não possuem o contato com a realidade da Educação no Campo e que atuam com estudantes do campo.

A formação continuada deve atender os professores em suas necessidades. Os processos de formação continuada são valiosos se conseguirem aproximar a teoria da prática pedagógica. E só é significativa, quanto provoca mudanças na postura do professor, e essa mudança a partir dos recursos que ele dispõe, porém, dotado de uma fundamentação teórica consistente, lembrando que a educação não se resume 
à sala de aula ou a escola por este motivo as formações continuadas são importantes para os professores pois ampliam a visão do profissional sobre a educação brasileira.

\section{REFERÊNCIAS}

BRASIL. Lei ํㅜ 9.394, de 20 de dezembro de 1996. Estabelece as diretrizes e bases da educação nacional. Disponível em: < http://www.planalto.gov.br/ccivil_03/leis/19394.htm> Acesso em: 23 mar 2014

. Senado Federal. Plano Nacional de Educação. Brasília/DF, 2001. Disponível em: < http://unesdoc.unesco.org/images/0013/001324/132452porb.pdf> Acesso em: 23 jun 2014

,Conselho Nacional de Educação. Resolução CNE/CEB 1, de 03 de abr de 2002. Institui Diretrizes Operacionais para a Educação. Disponível em: < file:///C:/Users/Aldimir\%20Junior/Downloads/rceb001_02\%20(1).pdf/./. Acesso em: 08 mai 2014

. MATO GROSSO DO SUL. Lei № 2.787 de 24 de dezembro de 2003.

Dispõe sobre o Sistema Estadual de Ensino de Mato Grosso do Sul.

Ministério de Educação. Educação do Campo: diferenças mudando paradigmas. Brasília/DF, Secretaria de Educação Continuada, alfabetização e Diversidade. Cadernos SECAD no 02., 2007 p. 81

. Ministério da Educação. Resolução no 02, de 28 de abril de 2008. Estabelece diretrizes complementares, normas e princípios para o desenvolvimento de políticas públicas de atendimento da Educação Básica do Campo. Disponível em: < http://portal.mec.gov.br/cne/arquivos/pdf/2008/rceb002_08.pdf> Acesso em: 23 mar 2014

FERNANDES, Elisangela. Desigualdade em campo. Revista Educação [on-line]. Reportagem. 2011.

Disponível em: 
http://revistaeducacao.uol.com.br/textos/163/artigo234867-1.asp> Acesso em: 29 mar 2014

NETO, Luiz Bezerra. A educação rural no contexto das lutas do MST. 2009.

SOUZA, Maria Antonia. Educação do campo: políticas, práticas Pedagógicas e produção científica. Educ. Soc., Campinas, vol. 29, n. 105, p. 1089-1111, set./dez. 20081089 Disponível em http://www.cedes.unicamp.br Acesso em: 27 mar 2014

Enviado: Agosto, 2019.

Aprovado: Janeiro, 2020. 